\title{
AVALIAÇÃO ISOCINÉTICA DO TORQUE DE EXTENSÃO E FLEXÃO DE JOELHOS EM
}

\section{PRATICANTES DE POWERLIFTING}

\author{
Cassiano A. Massafera*, Adonias O. F. de Souza, Erick G. P. de Lucena, Bárbara B. P. Gonçalves, Marco C. \\ Uchida.
}

\section{Resumo}

O Powerlifting é um esporte que tem como objetivo a execução de exercícios com a maior intensidade possível, dentro das regras estabelecidas pelas organizações da modalidade. Esse é caracterizado como um esporte de força, que possui o agachamento, supino e levantamento terra como exercícios principais. O presente estudo teve como objetivo a avaliação do pico de torque nos movimentos de extensão e flexão de joelhos. Os participantes $(n=26)$ foram divididos em dois grupos, 1) praticantes de powerlifting, e 2) individuos fisicamentes ativos. O método de avaliação foi a dinamometria isocinética através do equipamento da marca Biodex, onde mensurou-se a relação de pico de torque dos extensores e flexores dos joelhos em duas velocidades, $60 \%$ e 180\%. Resultados: A média do pico de torque dos praticantes de powerlifting foi maior nas duas velocidades. Conclusão: Os praticantes de powerlifting possuem maior torque de extensão e flexão de joelho comparados a indivíduos fisicamente ativos . E-mail: cassiano.am@hotmail.com

\section{Palavras-chave: \\ Membros inferiores; Força; Potência..}

\section{Introdução}

O powerlifting é um esporte de força que apresenta o agachamento e levantamento terra como exercícios que trabalham membros inferiores, tendo recrutamento de grupo musculares como quadríceps e isquiotibiais atuando diretamente sobre a articulação do joelho' ${ }^{1}$. Buscamos então, avaliar o torque gerado pelo membro dominante dos praticantes de powerlifting (PP) e do grupo fisicamente ativo (C). Foi feito um teste em um dinamômetro isocinético, nele coletamos o pico de torque (PT) dos movimentos de flexão (FLEX) e extensão (EXT) de joelho em praticantes de powerlifting e do grupo controle.

\section{Resultados e Discussão}

A amostra foi de praticantes de powerlifting $(n=13)$ e treze indivíduos fisicamente ativos $(n=13)$. Foi realizado um teste no dinamômetro isocinético, com 5 repetições máximas na velocidade $60 \%$ e 15 repetições máximas a $180 \%$ s de flexão e extensão de joelhos, com intervalo de 3 a 5 minutos, computando os valores de pico de torque (Nm). Análise estatística foi feita pelo test t não pareado. A média do pico de torque dos praticantes de powerlifting foi significativamente maior que o do grupo controle $(p<0,05)$ na extensão e flexão na duas velocidades $60 \%$ e $180 \%$ s. Figura 1.
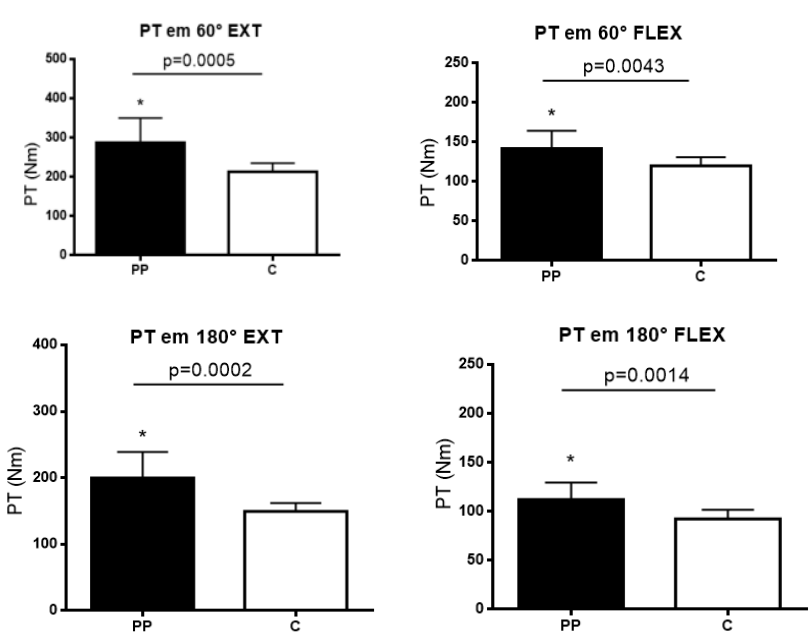

Figura 1. Média dos Valores de pico de torque (PT) dos grupos (PP) e (C) de (EXT) e (FLEX) nas velocidades $60 \%$ e $180 \%$ s. * $p<0,05$ diferença significativa entre grupos.

\section{Conclusões}

Os praticantes de powerlifting possuem maior torque de extensão e flexão de joelho comparados a indivíduos fisicamente ativos, tanto em média e como alta velocidade de movimentos.

\section{Agradecimentos}

Agradecimentos ao Programa de Iniciação Científica e Tecnológica da UNICAMP e Conselho Nacional de Desenvolvimento Científico e Tecnológico (CNPq). 